\title{
Safety Education and Training: On Site Lessons for Workers in Selected Construction Sites of Lusaka District
}

\author{
Kaiko Mubita $^{{ }^{*}}$, Inonge Milupi ${ }^{2}$, Pauline Namakau Monde ${ }^{3}$, Steriah, M Simooya ${ }^{4}$, Timothy \\ Kamuzu Phiri ${ }^{5}$ \\ 1,2,3,4,5 The University of Zambia, School of Education Department of Language and Social Sciences Education, \\ Lusaka, Zambia
}

*Corresponding Author: Kaiko Mubita, The University of Zambia, School of Education Department of Language and Social Sciences Education, Lusaka, Zambia

\begin{abstract}
This paper proposes a training guide that general workers could undergo in order to enhance safety in construction sites. The programme was motivated by reports and literature that some construction sites general workers got injured at work often. This scenario was likened to low levels of education related to their job description. Because of the low levels of education related to their jobs, some general workers were not aware of their environments and therefore could not easily identify risks and hazards they were exposed to. The study employed a descriptive survey of selected construction sites in Lusaka district. Institutionalbased cross-sectional study was conducted at four construction sites conveniently sampled within Lusaka district. The study established that general workers on most construction sites visited had poor formal education levels. The low education levels observed among general workers in construction could expose them to hazards unknowingly. It was discovered that $63.3 \%$ of the work force had low qualifications related to construction activities General workers with low education levels could also lack necessary warns and precautions necessary to prevent possible accidents and risks. Therefore, this study recommended the need for safety education, through on-site lessons to provide general workers with instructions and warnings that provide awareness about potential hazards with an objective of minimizing injuries and their fatal consequences.
\end{abstract}

Keywords: Safety Education, Training, Training Programme, Construction Site

\section{INTRODUCTION}

Construction work involves a series of occupational hazards and risks. These may include risks such as working at heights, excavation work, lifting of materials and manual handling, and so on. To this effect, the construction industry is often classified as a high-risk industry as it has historically been plagued with much higher and unacceptable injury rates compared to other industries (Lopezvalcarcel, 2001). According to MacCollum (1995) accidents at construction sites are identified as a major public health problem throughout the world. Even though the number of fatal occupational accidents in the construction industry all over the world may not be easy to quantify as information on this issue is not readily available for most countries, it would be acceptable to estimate that at least 55,000 fatalities occur at construction sites around the world every year. This means globally one fatal accident occur in this sector approximately every ten minutes (Lopez-valcarcel, 2001). These accidents in the construction industry are attributed mainly to low education levels. For example, Summan et.al (2020) noted that the major cause of accidents and injuries in construction sites is the lack of awareness about occupational safety and lack of experience among the workers. The International Labour Organisation (ILO, 2020) also noted that in some developing countries, construction industry provided a traditional point of entry for less educated workers.

The U.S. Bureau of Labour Statistics (2010) also noted that educational attainment of employees in construction is lower than in most other industries except for agriculture. According to the U.S. Bureau of Labour Statistics (2010) in 2010, about $40 \%$ of construction workers had some postsecondary education, in contrast with $62 \%$ of the total workforce. This low level of education noted among construction workers could be a recipe for risk and accidents in the construction sector. This is because the less educated workers in construction industry may not be aware of hazards and risks 
related to their jobs. They could, therefore, cause accidents that could harm themselves and others in the same environment.

According to Alli (2008: 35) education and training provide individuals with the basic theoretical and practical knowledge required to carry out their trade or occupation successfully and to fit into the working environment. Because of the importance of occupational safety and health, measures should be taken to include these subjects in education and training at all levels in all trades and professions, including higher technical, medical and professional education. Education and training are the foundations for establishing improvement in Occupational Health and Safety (OHS) in any sector. He explains that sound basic education for work, certified induction and refresher training and certified company-specific training as part of long-life learning are crucial for the implementation of effective health and safety hazard prevention programmes. These must be supplemented by specific seminars, refresher training and improvement programmes-for trainers and for managers, supervisors and workers. The foregoing was also noted by Mubita et.al (2020) who noted that education and training is a factor in general environmental safety.

A National Institute for Occupational Safety and Health (NIOSH,1998) study also concluded that training in developing and maintaining effective hazard control activities is a proven and successful method of intervention. People who are properly trained in their jobs and are aware of the hazards associated with the role they or those they supervise perform are less likely to suffer or cause injury. However, in the Zambian scenario, Tente (2016) noted that the cause of accidents in construction industry was lack of safety training, among others. General workers at construction sites have very low educational attainment. They are mainly involved in job-on-training. This may expose them to certain accidents within their working environment because of ignorance because they lack the education related to their job description.

With reference to the foregoing, a growing body of evidence suggests that workers killed or injured on the job are often workers who arrive on the job with little or no formal training or limited English language skills. These factors frequently result in workers carrying out risky work without proper training and education and, therefore, exposes them to construction risks and hazards.

Against this background, this study explored the role which education and training could play as an intervention method in maintaining effective hazard control activities in selected construction sites of Lusaka district. The study further drew actual on-site lessons for general workers with low education levels to ease their training in safety.

2. AIM

The study aimed at addressing safety issues in selected construction sites of Lusaka district through on-site safety education and training.

\section{RESEARCH OBJECTIVES}

This study was informed by the following objectives:

- To identify hazards inherent in selected construction sites in Lusaka district

- To draw a training programme for workers at selected construction sites in Lusaka district

\section{Conceptual Framework On SafeTy Training ANd Education}

There are a number of psychological mechanisms linking the effect of safety education and training to safety behaviour and accident involvement at the individual level. One such model is that one developed by Tharenou et.al. (2007). According to Tharenou et.al. (2007) safety education and training has indirect effects on organisational outcomes (such as accident and injury rates) through its influence on the perceptions and attitudes of employees. There is support in the training literature that psychological variables (at an individual level) mediate the effect of training on organisational outcomes (Tharenou et.al. 2007). This model is consistent with Holton's Training Evaluation Model (Holton, 1996), which includes outcomes at three levels: learning, individual performance and organisational performance as indicated by figure 1 . 


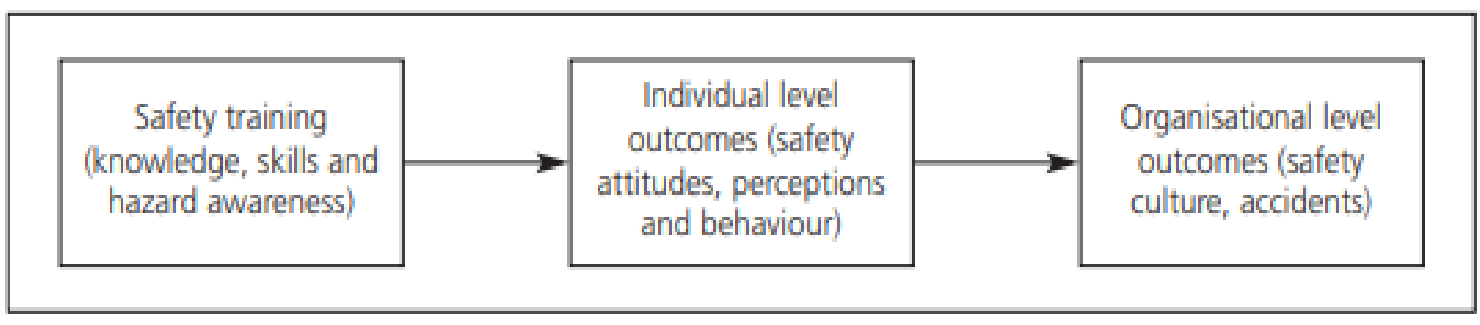

Figure1. Behavioural model of the impact of safety training on safety culture

Source: Clarke and Flitcroft, 2013

\section{AN OVERVIEW OF LITERATURE}

\subsection{Safety Education and Training}

Safety education is the teaching of specific knowledge, skills and understanding that people need in order to stay safe in a given situation. According to Kapur (2020) safety education is the education that aims to impart knowledge and understanding to the individuals in terms of measures and strategies to promote safety. To promote good health and well-being physically as well as psychologically Kapur (2020) note that individual need to be safe.

According to US Department of Labour (2020) education and training are important tools for informing workers and managers about workplace hazards and controls so they can work more safely and be more productive. Education and training also provides workers and employers with an understanding of the safety and health program itself so that they can contribute fully to its development, monitoring and implementation in the long run (Mubita, Milupi, Monde, and Simooya, 2020).

Blake has explained the difference of education and training. He says, "Education deals with developing the mind, broadening knowledge and understanding (RLS Human Care, 2020). Education in a specific subject means acquisition of broad and thorough knowledge in that subject (RLS Human Care, 2020). Training deals with the development of skill in performance. In industry it refers to the skilled trades as applied to safety. Education and training are not completely separable; each participates to some extent of the nature of the other. Safety Education is for developing safety mindedness a vivid awareness of the importance and correcting conditions and practices that might lead to injury (RLS Human Care, 2020). Safety training is for developing the worker's skill in the use of safe work techniques and practices. It is described as a detailed extension of the educational safety programmed applied to specific occupation, processes, jobs or activities" (RLS Human Care, 2020).

According to OSHA (2020) education and training provides employers, managers, supervisors, and workers with the following:

- Knowledge and skills needed to do their work safely and avoid creating hazards that could place themselves or others at risk.

- Awareness and understanding of workplace hazards and how to identify, report, and control them.

- Specialized training, when their work involves unique hazards.

Effective training and education can be provided outside a formal classroom setting. Peer-to-peer training, on-the-job training, and worksite demonstrations can be effective in conveying safety concepts, ensuring understanding of hazards and their controls, and promoting good work practices (US Department of Labour, 2020).

\subsection{Why Training and Education for safety?}

French writer Victor Hugo once said in 1981, "No cause can succeed without first making education its ally". This adage fully applies to management of safety and health at workplaces. It is also very relevant to employers and employees at all levels for any industry, construction industry inclusive (Hecker, 2006). A construction site is increasingly becoming complex due to use of technology in its operations. Therefore, there are new demands for greater understanding of the causes and means of prevention of accidents, injuries and illnesses (Hecker, 2006). 
According to Hecker (2006) education is one of the primary tools needed to achieve the goals of reducing occupational injuries and illnesses and promoting occupational safety and health apart from engineering and enforcement. The overall rationale for training and education is to improve awareness of safety and health hazards, to expand knowledge of the causes of occupational illness and injury and to promote the implementation of effective preventive measures. The specific purpose and procedure for education and training will always vary for different target audiences and stakeholders (Hecker, 2006).

\subsection{Benefits of proper Safety Education and Training in Construction Industry}

Training and education contribute towards making employees competent in health and safety and also help the organisation avoid the distress that accidents and ill health may cause. Education and training and can also help you avoid the financial costs of accidents and occupational ill health (Health and Safety Executive, 2020).

According to OSHA (2020) there are many common construction hazards can be contained or avoided if proper safety training is provided. A safe workplace is believed to reduce overall construction costs. For example, proper safety training can reduce insured losses, administrative penalties/fines and litigation and attorney's fees (Construction Executive, 2020).Regardless of delays or looming deadlines, safety training and education should never be viewed as a disposable task. It is critical that each and every employee, even seasoned veterans, attend safety meetings and training on a regular basis. Just the simple fact that regular meetings keep safety on the minds of employees can be beneficial. Managers and supervisors need to invest the time in providing relevant and useful safety instruction and guidance. By making safety a priority, contractors can significantly reduce worksite injuries and deaths.

\section{Methodology FrameWORK}

A construction site-based cross-sectional study was conducted to assess occupational hazards among building construction workers in selected sites of Lusaka city. Unstructured interviews and focus group discussions were used as data collection methods. This was because of the interpretive nature of the study. Using homogeneous and expertise purposive sampling, a sample size of 30 construction site workers was sampled. Thematic data analysis was utilised for this study. The researchers closely examined emerging data to identify common themes, topics, ideas and patterns of meaning that came up repeatedly. These were then presented as thick narrative descriptions as below.

\section{RESULTS AND DISCUSSION}

\subsection{Socio-Demographic Characteristics of Workers}

Socio-demographics are characteristics of a population in a given study. In this study, characteristics such as age, education level, occupation, education level, were considered and asked to participants. This helped in data analysis.

A total of 30 construction workers were interviewed in this study. Out of this number, 25 (83.3\%) were male and $5(16.7 \%)$ were female. The majority of the employees belonged to the age group of 14-29 years (40\%). From the collected data, only a few workers had obtained either diploma or certificate in their specialisations (Certificate: $16.7 \%$ Diploma: $3.3 \%$ ) education. The majority were not really trained in their duties $(80 \%)$. Table 1 summarises socio-demographic characteristics of the participants in this study.

Table1. Socio-Demographic characteristics of building construction workers

\begin{tabular}{|l|l|l|l|}
\hline Characteristic & & Frequency & Percent \\
\hline Sex & Male & 25.0 & 83.3 \\
\hline & Female & 5.0 & 16.7 \\
\hline Age & $14-29$ & 12.0 & 40.0 \\
\hline & $30-44$ & 11.0 & 36.7 \\
\hline & 45 Plus & 6.0 & 23.3 \\
\hline Educational Level & Cannot Read and Write & 4.0 & 13.3 \\
\hline & Read and Write Only & 6.0 & 20.0 \\
\hline
\end{tabular}


Safety Education and Training: On Site Lessons for Workers in Selected Construction Sites of Lusaka District

\begin{tabular}{|l|l|l|l|}
\hline & Elementary & 9.0 & 30.0 \\
\hline & Secondary School Education & 5.0 & 16.7 \\
\hline & Certificate & 5.0 & 16.7 \\
\hline & Diploma & 1.0 & 3.3 \\
\hline Occupation & Daily Labourer & 11.0 & 20.0 \\
\hline & Plasterer & 6.0 & 9.1 \\
\hline & Carpenter & 4.0 & 14.5 \\
\hline & Welder & 4.0 & 7.3 \\
\hline & Electrician & 3.0 & 3.6 \\
\hline & Painter & 1.0 & 1.8 \\
\hline & Driver & 1.0 & 1.8 \\
\hline
\end{tabular}

Source: Field data (2020)

From the details shown on table 1, it is notable that most of the workers in selected construction sites in Lusaka city had low education levels related to their job descriptions. As can be seen, about $63.3 \%$ of the work force had low qualifications related to construction activities. Because of the low level of education related to their jobs, some general workers were not aware of their environments and therefore could not easily identify risks and hazards they were exposed to. This could give rise to injuries and fatalities in certain cases.

The foregoing arguments are supported by many reports that found a consistently elevated risk for injury among workers with lower educational attainment (Breslin 2008; Strong and Zimmerman 2005). According to Breslin, 2008, the increased risk for injury among uneducated workers is due to unfamiliarity with job tasks or work environment, failure to recognize workplace hazards, ineffective or inadequate safety training, and differential exposure to more hazardous tasks at the beginning of a job (Breslin and Smith 2006).

According to Breslin (2008) workers with lower levels of education appear to be particularly vulnerable, possibly because of their greater exposure to physical demands or other hazards. Additional evidence from Pueyo, Toupin and Volkoff (2011) suggests that educated workers plan ahead in order to limit fatigue and avoid stressful emergency situations much more than do their less experienced coworkers. Mubita, Monde, Simooya and Phiri (2016) also noted that education is key to environmental safety.

\subsection{Major Hazards at Construction Sites in Lusaka District}

The second objective for this study looked hazards inherent in selected construction sites of Lusaka City. Therefore, participants in this study were asked about the common hazards they were exposed to in their respective construction sites. The identification of hazards inherent in the construction sites was important because it helped in specifications needed to design a learning guide for workers. It helped in identifying the actual points of need for safety education and training for workers in selected construction sites of Lusaka city. The following hazards were reported by participants:

\section{(a) Working at height}

Participants in this study noted that some of their working activities involved working at height. They had to climb to carry out certain tasks. Participants reported that they were exposed to unstable working surfaces particularly those off the ground and these could expose them to risks of falling. These included climbing on ladders and scaffolds when plastering, bricklaying and so on. All such activities exposed them to risks of falling and consequently get injured. One participant put it concerns with regard to working at height as follows:

As workers at this company, we are exposed to risks of falling because we sometimes work from height. We climb to do welding, brick laying, plastering, painting, and other jobs. We usually climb on scaffolds and ladders. The ladders and scaffolds are sometimes not strong enough to support our work and increase the risk of falling.

According to British safety Council (2020) falls from height are the biggest cause of fatal injuries at work. The Health and Safety Executive (HSE, 2020) statistics show that 40 workers were killed as a result of a fall from height in 2018/19. Since work at height is carried out every day within the 
construction industry, this is a daily risk that workers must be prepared for. This frequency of falls from height was also reported by participants in this study.

Risks from falls from height in selected construction sites in Lusaka city can be minimised by implementing training in safe working practice (Mubita, 2016). The risks can also be reduced or minimised by the use of Personal Protective Equipment (PPE) and fall protection systems. More so, to reduce risks associated with falls from height in construction sites, there is need to ensuree that equipment used is fit for tasks and activities performed such as using the correct ladder, correct material and equipment.To this effect, it is recommended that Suitable training be given to all employees who work at height. Workers should be should be trained in working on different pieces of equipment and surfaces, such as how to work safely on scaffolding, ladders, and roofs (High Speed Training, 2019).

\section{(b) Slips, Trips and Falls}

According to participants in this study, slips, trips and fall hazards were highly experienced in their construction sites. According to them, hazards resulting from slips, trips and falls were more frequently experienced as compared with other hazards in selected construction sites of Lusaka city. Slips and trip hazards usually affected balance and accounted for the majority of work-related injuries in construction sites. This was because most construction sites had uneven surfaces and unstable terrain. One of the participants expressed his experiences as follows:

Our construction site here has uneven surfaces. We also have cables, stones and other constructions materials and machinery where we strip on as we walk around the sites. This happens mainly when it is dark, at night when we cannot see properly. There's also wet debris that causes slipping, especially in rain season. The slipping and tripping happens on daily basis.

In selected construction sites of Lusaka city, slips, trips and falls were reported to be so frequent by participants in this study as noted above. The Occupational Health and Safety Administration, (OSHA, 2020) requires employers to protect against these hazards. Health and SafetyExecutive (2018) reports that thousands of construction workers are injured every year following a slip or trip, and that most of these could be avoided by effectively managing working areas and access routes, such as stairwells and footpaths. One of the most effective ways of protecting construction workers is by offering training and education on site. The risks due to slips, trips and falls could be minimised by teaching workers on how to keep keep walkways and stairways dry, remove debris in passages or walkway and materials which could cause slips. Slips, trips and fall could also be minimised by the use of temporary surfaces to cover holes and excavations. Workers could also be encouraged to wear non trip footings whilst at work. Management could also use warning signs and also implement protocols for removing spills and for working in bad weather.

\section{(c) Manual handling}

According to participants in this study, their construction site activities involved more of pulling, pushing and lifting loads using hands. This exposed them to risks of musculoskeletal disorders. This also made them get more fatigued and tired physically. They explained that they were exposed to manual handling risks on daily basis and that most casual workers were at risk. They also noted that their sites had less machinery and tools to use in lifting and loading. One of the participants explained his experiences about dangers of manual handling as follows:

Our construction site has a small number of machinery. Therefore, most of us casual workers work using our hands. We pull, push and carry most materials using our own hands. This makes us tired and feel fatigued. We experience back pains and muscular pains too.

Manual handling activities generally requires some form of training if employees have to be safeguarded. This is due to some technicalities involved in carrying out varying tasks in construction sites. There is need to teach workers how to lift and carry loads safely. This is supported by High Speed Training (2019) who proposed that where duties involve manual handling, adequate training must be provided to the workers. If an employee is required to use lifting equipment, they must be trained in how to use this and a test should be taken to check their ability to use the equipment safely.The risks of manual handling can also be reduced by conducting full risk 
assessments and introducing protocols and working processes which eliminate risk of prolonged use (Mubita, Milupi, Monde, Simooya, 2020). Moreover, full and regular training in what constitutes safe manual handling.

\section{(d) Collapse}

Participants in this study explained that construction activities in their sites involved excavations and the building of trenches. According to participants, at any given time, collapses could occur in excavations and trenches, scaffolding and walls, through undermining, dangerous structures and accidental collapse as structures are installed, erected or demolished. This could expose them to accidents. One participant explained the worry of collapse as following:

We are involved in digging trenches among other activities. These trenches, pits or holes tend to collapse at times, especially in the rain season when soils are loose and wet. This put workers at risk.

From the foregoing, it is clear that something has to be done to minimise risks related to collapse of structures in construction sites. Health and Safety Executive (2020) suggest ways of minimising risks due to collapse of structures in construction sites by implementing protective systems for trenches and workers using them. Moreover, risk assessment of buildings and sites should be carried out to ascertain levels of risks workers could be exposed to. Training the construction workers is another way of minimising the risks related to collapse of trenches and structures. Mubita, Monde, Simooya and Phiri (2016) also noted that education and training is a factor in improving safety in working environments.

\section{(e) Automobiles}

Automobiles were noted as one of the hazards workers in construction sites faced in selected construction sites in Lusaka district. With vehicles, equipment and movement of materials, the busy nature of construction sites meant that moving objects frequently resulted in on-site injuries and sometimes fatalities. According to participants, risk came from cars, cranes and plants, including forklifts, plus the actual volume of traffic which formed part of a working site. Participants also noted that significant movement of automobiles usually occurred within sites and this put workers at risk of injuries, noise and even fatalities. According to one of the participants in this study, transporting construction materials within the site presents notable hazards. The explanation was put as follows:

Within a construction site, materials have to be transported from one place to the other. Workplace transports present significant hazards on our construction sites. Automobiles that present hazards are vehicles, cranes, dumpers, forklift trucks, and excavators. These provide serious risk of accidents to workers on site.

From the foregoing, it was clear that selected construction sites in Lusaka city faced hazards related to automobiles. Accidents were expected as a result of collision and so on. The risks are also from overturn and collisions with pedestrians or plant/equipment. Even the community around these construction sitesare at risks if not managed correctly.

Automobile risks in selected construction sites in Lusaka city could be minimise byusing engineering controls. Barriers could be put around construction sites to block community members from noises and risks of collision with automobile. The workers and community at large could also be taught about safety preventive measures.

\section{(f) Electricity}

Participants in this study explained that they were in danger of exposure to electrical hazards. The electric hazards could result in dangers related to shocks and arc flashes or blasts that caused worker deaths and numerous injuries. According to participants, electricity was hazardous to all construction workers exposed to power. One of the workers explained his experiences as follows:

We are exposed to dangers of electricity in many ways in this site. We sometimes use electric driven machines and walk over electric cables. This put us in danger of shocks and even electrocution if not careful. When working practices are disorganised and rushed, such as undertaking electrical work in wet conditions or using non-professionals to complete electrical work, electricity presents additional hazards. 
Inspections from the selected construction sites in Lusaka city reviewed those electrical hazards came from improper wiring, damaged tools and equipment, damaged insulation and so on. This was also noted by the Occupational Safety and Health Administration (OSHA, 2015), who put it that electrical hazards that are typically found at construction sites include those arising from improper grounding, exposed electrical parts, inadequate wiring, damaged insulation, overloaded circuits, damaged tools and equipment. These electrical hazards have the potential of causing shocks or even electrocution if not well managed. Therefore, in order to minimise risks related to electrical hazards in construction sites, only qualified electricians should be allowed to undertake electrical works (OSHA, 2015). Moreover, site administrators can also make us of safety warnings signage and barrier systems to protect those working alongside overhead cables and power lines. The workers and local community can also be taught about electrical safety in order to enhance safety (Mubita, Milupi, Monde, Simooya, 2020).OSHA (2015) also proposes that employees should be trained to be thoroughly familiar with the safety procedures for their particular jobsto prevent electrical accidents.

\section{(g) Noise}

According to the Centre for Disease Control and Prevention (2018) 14\% of construction workers report having a hearing difficulty due to the hazardous noise at their work. Construction workers operate equipment above the $85 \mathrm{dBA}$ level (Center for Disease Control and Prevention, 2018). Noise was identified as one of the hazards experienced by workers in selected construction sites of Lusaka district. According to workers sampled, their construction sites working environment were both busy and noisy. This noise could be hazardous for workers, and also could expose them to long-term, repetitive sounds such as drills and compressors which can lead to short or long-term problems, including hearing loss. Construction site noise also presented a distraction which resulted or lead to accidents. One of the workers explained dangers of noise as follows:

Our machines and other automobiles make a lot of noise in this construction site. This affects our attention and hearing. Because of this, we may be distracted and fail to pay attention to specifics in our duties. This may cause accidents in the long run. The noise we experience also may result in hearing loss eventually.

This noise noted in selected construction sites in Lusaka could prove injurious to workers in terms of hearing loss. The noise could be minimised by correct use, checking and maintenance of PPE; carrying out noise risk assessments for workers and the public and by using noisy ground-breaking equipment. Because of the varying demographics work force, employers should be able to provide training in several languages in the selected construction sites in Lusaka district if possible. Training presentations can be purchased in various languages and can be used to fulfil some of the training requirements. Environmental Health and Safety (2020) also propose that construction workers must be educated to the fact that once they lose their hearing, it does not come back. Moreover, employees on site can use different types of hearing protectors to meet employee needs in terms of both compliance and user acceptance.

\section{Proposed Training Guide}

After identifying hazards inherent in the selected construction sites in Lusaka district, there was need to propose a training guide for workers. This guide is meant to provide a step-by-step reference for learning in order to avoid or minimise the risks to the identified hazards in construction sites. It provides on-site lessons for construction workers in order to make them aware of the hazards in their environment and also to provide sustainable solutions through education and training. The proposed training guide in this study was designed to provide guidance in the ability to achieve the following: Recognize hazards, assess the risk of those hazards, control hazards and prepare to respond to emergencies.

\subsection{A Proposed Lesson Plan For Construction On-Site Teaching And Learning}

In order to fully execute the teaching and learning for construction workers, a lesson plan is really needed as a guide to a step-by-step coverage of content. Figure 2 presents a lesson plan that could be of used in teaching of workers at construction site. 


\section{Name of Construction site:}

Unit/Topic

Date

Key Learning Area:

Category of learners:

\section{LESSON OUTCOMES}

By the end of the lesson, construction workers should be able to:

(a) identify hazards in their working environment

(b) evaluate the risk of hazards identified

(c) suggest sustainable mitigation measures to hazards identified

\section{Teaching/Learning Materials}

The following materials can be used when delivering this lesson:

- charts, actual materials used on-site, note book, pen, pencil

\section{Lesson Structure}

\begin{tabular}{|c|c|c|}
\hline Time & Introduction & Teaching Approaches \\
\hline 5 minutes & $\begin{array}{l}\text { What dangers are you exposed to in this construction site? } \\
\text { Expected answers } \\
\text { Dust, noise, electricity, slips, trips and falls, collisions from } \\
\text { automobiles }\end{array}$ & Question and answer \\
\hline $\begin{array}{l}30 \\
\text { minutes }\end{array}$ & 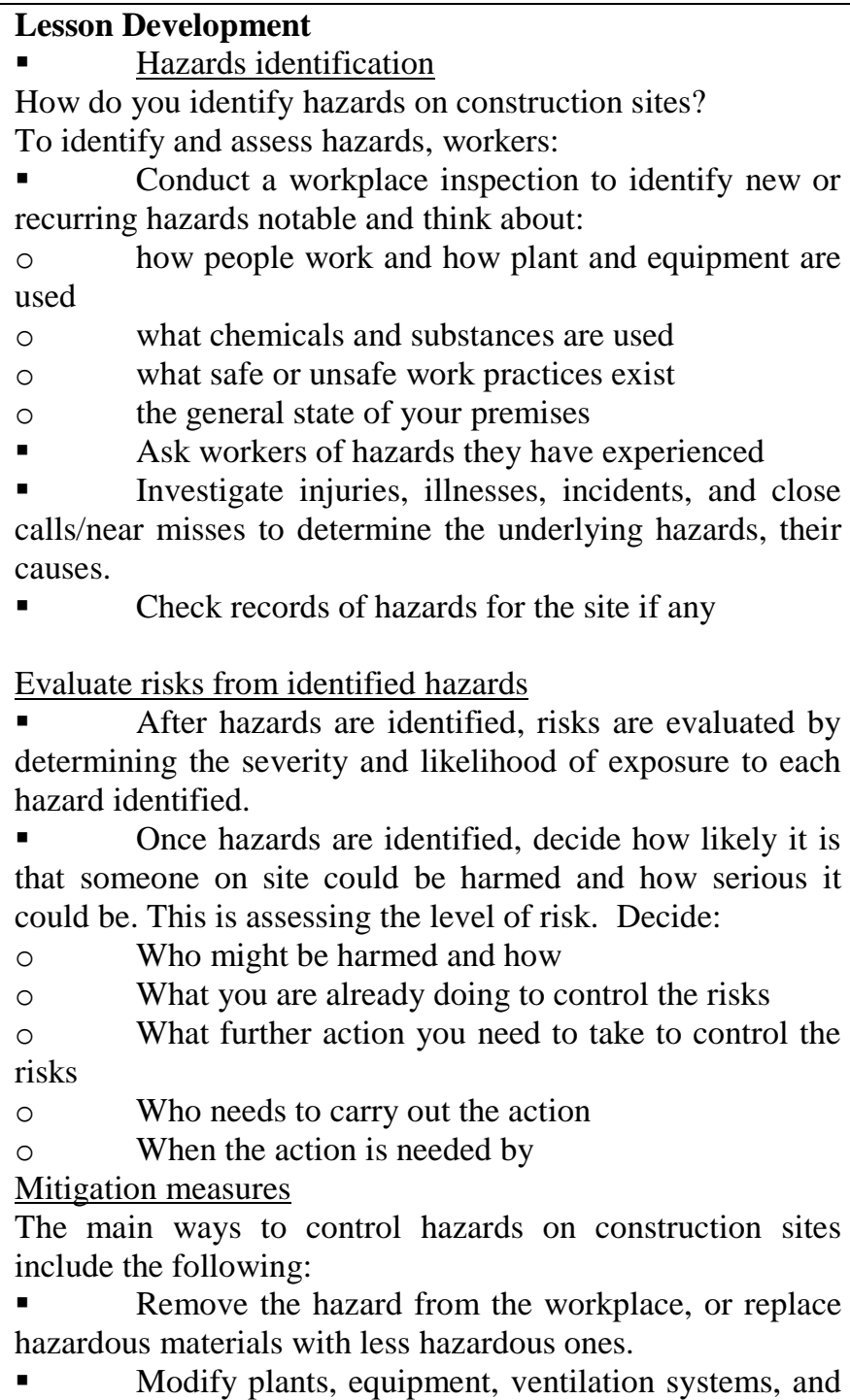 & $\begin{array}{ll}\text { - } & \text { Demonstrations } \\
\text { - } & \text { Exposition } \\
\text { - } & \text { Question and answer } \\
\text { - } & \text { Site excursion } \\
\text { - } & \text { Group tasks }\end{array}$ \\
\hline
\end{tabular}




\begin{tabular}{|c|c|c|}
\hline & $\begin{array}{l}\text { processes that reduce the source of exposure to hazards. } \\
\text { - Change the way the work is done, change policies } \\
\text { and other rules, and work practices, this could include } \\
\text { training, housekeeping, and equipment maintenance, and } \\
\text { personal hygiene practices. } \\
\text { - Using Personal Protective Equipment }\end{array}$ & \\
\hline Time & Conclusion & Teaching Approaches \\
\hline 5 minutes & $\begin{array}{l}\text { - Ask workers to demonstrate what was taught to } \\
\text { them } \\
\text { place } \\
\text { Qsk oral questions to find out if learning has taken } \\
\text { Questions and answer session } \\
\text { 1. } \\
\text { site? How do you identify hazards in the construction } \\
2 . \\
\text { 3. }\end{array}$ & - Question and answer \\
\hline
\end{tabular}

\section{Practical Exercise}

In groups of 3, carryout the following tasks:

(b) Identify hazards at your construction site

(c) Evaluate the risks of the identified hazards

(d) Suggest sustainable mitigation measures to the identified hazards

(e) Hand in a report in 3 within days

\section{Performance Evaluation}

The philosophy of performance evaluation states that the evaluation process exists to facilitate the improvement of instruction. In this context, evaluation is done to rate levels of achievement in the lesson delivered to construction workers on site. The evaluation procedures and associated instruments provide the framework for assessing teacher performance as it relates to the adopted performance criteria.

\section{CONCLUSION AND RECOMMENDATIONS}

From this study, it is evident that construction sites employ a lot of workers with low qualifications related to their jobs. Therefore, there is need to have onsite training for such workers in order to make them aware of safety and health issues within their working environments. On-the-job training at the worksite is appropriate for workers facing specific hazards found onsite. If the training and education has to be significant, a comfortable classroom facility within the worksite is strongly recommended. There should be real lesson planning and training for construction workers.

\section{ACKNOWLEDGMENT}

The authors would like to thank the following for permissions and funding for this study: Zambia Council of Construction and The University of Zambia, Directorate of Research and Graduate Studies

\section{REFERENCES}

[1] Alli, B.O. (2008). Fundamental principles of occupational health and safety. International Labour Office, Geneva

[2] Breslin F C, Smith P. (2005). Age-Related Differences in Work Injuries: A Multivariate, Population-Based Study. American Journal of Industrial Medicine 48 (1): 50-56. doi: 10.1002/ajim.20185.

[3] Breslin F C, Smith P. (2006). Trial by Fire: A Multivariate Examination of the Relation between Job Tenure and Work Injuries. Occupational and Environmental Medicine 63 (1): 27-32. DOI: 10.1136/oem. 2005.021006

[4] Breslin F C. (2008). Educational Status and Work Injury among Young People: Refining the Targeting of Prevention Resources. Canadian Journal of Public Health 99 (2): 121-24.DOI: 10.1007/BF03405458 
[5] British Safety Council. (2020).The top five construction site risks and hazards. Retrieved from https:// www.britsafe.org/publications/safety-management-magazine/safety-management- magazine/2020/the-topfive-construction-site-risks-and-hazards

[6] Centre for Disease Control and Prevention. (2018). Occupational Hearing Loss (OHL)

[7] Surveillance. Retrieved from https://www.cdc.gov/niosh/topics/ohl/construction.html

[8] Clarke, S and Flitcroft,C. .(2013). The effectiveness of training in promoting a positive OSH culture. The Grange Highfield Drive Wigston Leicestershire

[9] Environmental Health and Safety. (2020). The Hidden Risks of OSHA's Noise Standard

[10] Health and Safety Executive. (2020). Structural stability during excavations. Retrieved from https://www.hse.gov.uk/construction/safetytopics/excavations.htm

[11] Heath, ED. (1981). Worker training and education in occupational safety and health: a report on practice in six industrialized western nations. Am J Ind Med 2:379-403.

[12] Hecker, S. (2006). ILO Encyclopeadia of Occupational Health and Safety Chapter 18: Education and Training Fourth Edition. Retrieved from http://www.ilocis.org/en/contilo3.html/

[13] High Speed Training. (2019). Ten Common Construction Site Hazards. Retrieved from https://www.highspeedtraining.co.uk/hub/common-construction-hazards/accessed

[14] Holton, E. F., III. (1996). The flawed four-level evaluation model. Human ResourceDevelopment Quarterly, Sage Journals, 7(1), 5-21.

[15] International Labour Organisation (ILO, 2020). Recruitment practices pose problems for construction industry, Geneva, Switzerland,

[16] Kapur, R. (2020). Significance of Safety Education. Delhi, India

[17] Lopez-Valcarcel, A. (2001), Occupational safety and health in the construction work. African Newsletter on Occupational Health and Safety, 11(1), pp. 4-7.

[18] Summan, A, Emad A and Mansour B. (2020). Occupational accidents and injuries in construction industry in Jeddah city. Saudi Journal of Biological Sciences Pages 27 (8)1993-1998

[19] MacCollum D. V (1995). Construction Safety Planning. Van Nostrand Reinhold

[20] Mubita, K and Namafe, C.M (2016). Safety and Health Issues at Sefula Secondary School of Western Zambia. International Journal of Humanities Social Sciences and Education (IJHSSE) Volume 3, Issue 9, September 2016, PP 91-99 ISSN 2349-0373

[21] Mubita, K. (2016). Barriers to effective safety and health management at Sefula secondary school in western Zambia. Asian Journal of Management Sciences \& Education Vol. 5(4) October 2016, pp 88-95

[22] Mubita, K., Milupi, I., Monde, P. N and Simooya, S.M. (2020). A Proposed Holistic Approach to Fire Safety Management in Zambian Markets. International Journal of Humanities Social Sciences and Education (IJHSSE), Vol 7, no. 11, 2020, pp. 93-101 doi: https://doi.org/10.20431 /23490381.0711011 National Institute for Occupational Safety and Health .(1998). Assessing Occupational Safety and Health Training. A Literature Review. 4676 Columbia Parkway Cincinnati, Ohio 45226-1998

[23] Mubita, K., Phiri, T. K., Monde, P.N. and Simooya, S.M. (2016). Safety and Health Issues in Selected Schools of Chibombo District in Central Province of Zambia.International Journal of Humanities Social Sciences and Education (IJHSSE)Volume 27, Issue 8, Pages 1993-1998. doi.org/10.20431/23490381.0310010

[24] Occupational Safety and Health Administration .(OSHA, 2015). Electrical Hazards, Construction Sites and Your Legal Rights retrieved from https://www.powers-santola.com/blog/electrical-hazards-constructionsites-and-your-legal-rights

[25] Pueyo V, Toupin C, Volkoff S. 2011. The Role of Experience in Night Work: Lessons from Two Ergonomic Studies.Applied Ergonomics 42 (2): 251-55doi:10.1016/j.apergo.2010.06.015

[26] Pueyo, V, Toupin, C and $\underline{s}$. Volkoff, S. (2011). The role of experience in night work: Lessons from two ergonomic studies. Applied Ergonomics, Volume 42, Issue 2, January 2011, 251-255

[27] RLS Human Care, (2020). Safety Induction, Education, and Training. Retrieved from https://rlsdhamal. com/methods-of-safety-education-and-training/accessed

[28] Strong, L.L, Zimmerman F J. (2005). "Occupational Injury and Absence from Work among African American, Hispanic, and Non-Hispanic White Workers in the National Longitudinal Survey of Youth. ”American Journal of Public Health 95 (7): 1226-32. 
[29] Strong L L, Zimmerman F J. 2005. "Occupational Injury and Absence from Work among African American, Hispanic, and Non-Hispanic White Workers in the National Longitudinal Survey of Youth." American Journal of Public Health 95 (7): 1226-32.

[30] Tharenou et.al. (2007). A review and critique of research on training and organization level outcomes. Science Direct, Human Resource Management Review 17 (2007) 251-273

[31] U.S. Bureau of Labor Statistics. 2010 Current Population Survey. Calculations by CPWR Data Centre

[32] US Department of Labour. (2020). Recommended practices for safety and health programmes. 200 Consttution Ave NW Washington DC, 20210.Retrieved from https://www.osha.gov/shpguidelines/

[33] Tente, P. (2016). Safety and Health in the Construction Industry in Zambia. Unpublished dissertation, the University of Zambia. Lusaka, Zambia

AUTHORS' BIOGRAPHY

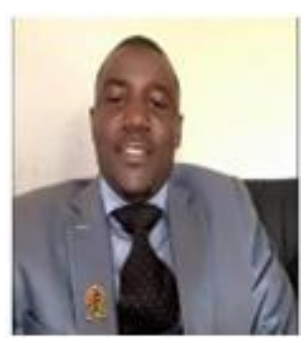

Kaiko Mubita (PhD), is a lecturer and researcher of Geography and Environmental Education at the University of Zambia. His research interests are in Occupational Health and Safety, Environmental Hazards and Disasters and Geography Education

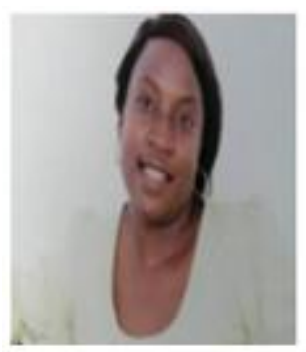

Inonge Milupi, $\mathrm{D}(\mathrm{PhD})$, is a lecturer and researcher of Environmental Education at the University of Zambia and a Post-Doctoral fellow at the University of Waterloo in Canada. Her research interest includes Environment and Society, Climate Change, Gender, Natural Resource Conservation and Indigenous Knowledge

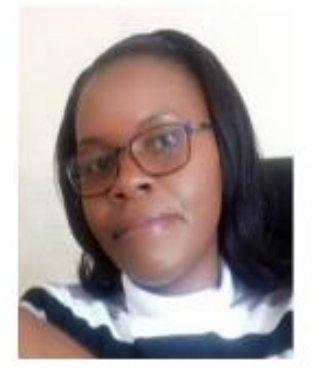

Pauline N. Monde is a lecturer and researcher at the University of Zambia in the Department of Language and Social Sciences Education. She is currently enrolled for $\mathrm{PhD}$ in Environmental Education at the same institution. Her areas of research interests include but not limited to Environmental Management, Environmental Governance and Ecological issues.

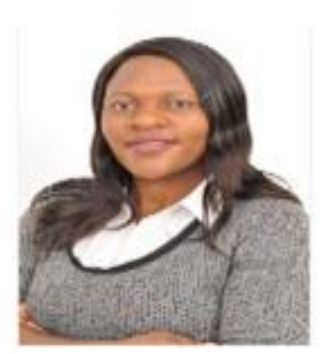

Steriah M. Simooya, is a lecturer and researcher at the University of Zambia in the Department of Language and Social Sciences Education. Her areas of research interest include but not limited to Environmental Management, Environmental Journalism and Environmental Education

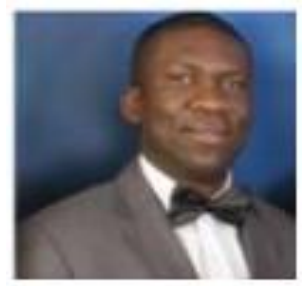

Timothy K. Phiri, is an environmental activist based in Lusaka, Zambia. He a former Environmental Education lecturer in the Department of Language and Social Sciences Education, School of Education at the University of Zambia. His research interests are in Environmental Sustainability, Agro ecology and Small Scale Farmers' Rights, Occupational Health and Safety and Mind-set and Behavioural Change. He is co-founder of Mizu Eco-Care- an environmental conservation Non-Governmental Organisation and also sits on the boards for Zambia Alliance for Agro ecology and Biodiversity (ZAAB) and Caritas Czech 
Safety Education and Training: On Site Lessons for Workers in Selected Construction Sites of Lusaka District

Republic Zambia. He is also the Chairperson for the Wildlife and Environmental Conservation Society of Zambia Lusaka Branch Committee.

Citation: Kaiko Mubita, et.al. "Safety Education and Training: On Site Lessons for Workers in Selected Construction Sites of Lusaka District" International Journal of Humanities Social Sciences and Education (IJHSSE), vol 8, no. 3, 2021, pp. 39-51. doi: https://doi.org/10.20431/2349-0381.0803004.

Copyright: (C) 2021 Authors. This is an open-access article distributed under the terms of the Creative Commons Attribution License, which permits unrestricted use, distribution, and reproduction in any medium, provided the original author and source are credited. 